\title{
PENINGKATAN NILAI EKONOMI MELALUI DIFERSIVIKASI USAHA TANAMAN PANGAN DAN SAPI BALI
}

\section{Increasing Economic Values Through DifersivicationFood Crop Business And Bali Cows}

\author{
Supardi Rusdiana, Diana Andrianita Kusumaningrum dan Chalid Talib \\ Email: s.rusdiana20@gmail.com \\ Balai Penelitian Ternak Ciawi-Bogor Po.Box. 221 Bogor Jawa Barat
}

\begin{abstract}
ABSTRAK
Tujuan tulisan ini adalah untuk mengetahui peningkatan nilai ekonomi melalui difersivikasi usaha tanaman pangan dan sapi Bali di peternak. Penelitian ini dilakukan di Desa Maccini Baji Kecamatan Bajeng Kabupaten Gowa Sulawesi Selatan 2018. Penelitian menggunakan metoda survei dengan menggunakan kuisioner dan wawancara terhadap 26 petenak sapi Bali. Data primer diperoleh dari peternak dan data sekunder diperoleh dari Dinas setempat. Data dianalisis secara deskriptif, kuantitatif dan analisis ekonomi. Tujuan tulisan ini adalah untuk mengetahui peningkatan nilai ekonomi melalui difersivikasi usaha tanaman jagung dan sapi Bali di peternak. Hasil penelitian menunjukkan keuntungan bersih dari usaha tanaman jagung sebesar Rp.1.356.075,-/tahun dengan R/C sebesar 1,4. Keuntungan bersih dari usaha dapi Bali sebesar Rp. 4.346.500,-/tahun dengan R/C sebesar 2,07. Secara analisis ekonomi diversifikasi usaha layak untuk dilanjutkan, karena selain untuk mengoptimalkan lahan pertanian juga untuk menanggulangi resiko kegagalan panen. Manfaat limbah jerami jagung sebagai pakan sapi Bali, keuntunagn peternak dengan waktu yang bersamaan. Difersivikasi usaha tanaman jagung dan sapi Bali di peternak secara ekonomi layak untuk diushakan kembali, dilihat dari nilai R/C >1.
\end{abstract}

\section{Kata kunci : peningkatan nilai ekonomi, difersivikasi usaha}

\section{ABSTRACT}

The purpose of this paper is to determine the increase in economic value through diversification of the business of food plants and Bali cattle in farmers. This research was conducted in Maccini Baji Village, Bajeng Subdistrict, Gowa Regency, South Sulawesi 2018. The research used a survey method using questionnaires and interviews with 26 Balinese cows. Primary data were obtained from farmers and secondary data were obtained from the local Dinas. Data were analyzed descriptively, quantitatively and economically. The purpose of this paper is to find out the increase in economic value through the diversification of the Bali corn and cattle business in breeders. The results showed a net profit from the corn crop business of IDR.1.356.075/year with an R/C of 1.4. The net profit from Bali's dapi business is IDR.4.346.500/year with an R/C of 2.07. From an economic analysis, business diversification is feasible, because in addition to optimizing agricultural land, it is also to overcome the risk of crop failure. The benefits of corn straw waste 
as Bali cattle feed, profits of farmers at the same time. The diversification of the Bali corn and cattle business in cattle is economically feasible to try again, judging by the $R / C$ value $>1$.

Keywords: increase in economic value, diversification of business

\section{PENDAHULUAN}

Potensi wilayah Desa Maccini Baji Kecamatan Bajeng Kabupaten Gowa Sulawesi Selatan cukup baik dan mendukung untuk perkembagan sapi Bali. Perkebangan sapi Bali dapat didukung dengan adanya limbah hasil tanaman pangan seprti jagung, padi dan lainya. Melalui difersivikasi usaha menjadi salah alternatif dalam upaya untuk meningkatkan nilai ekonomi peternak dan mendaptkan kuntunagn dengan waktu yang bersamaan. Dukungan tersbut bukan dilihat dari ketersediaan pakan hijauan dan limbah dari tanaman pangan saja, melainkan dengan ketersediaan tenaga kerja peternak yang dapat mempengaruhi kinerja difersivikasi usaha. Ketersediaan tenaga kerja keluarga peternak masih cukup tinggi, sehingga mendukung usaha pertanian dan sapi potong Bali. Sumber daya alam, manusia dan modal yang dapat di manfaatkan sebagai peran penting untuk pertumbuhan ekonomi (Demitria et al., 2006). Sumber daya manusia merupakan proses untuk meningkatkan pengetahuan, kreativitas kerja dalam meningkatkan usahanya (Dewi dan Mairika 2008).

Pada perspektif makroekonomi, akumulasi produktivitas sumberdaya manusia dan inovasi teknologi mendorong pertumbuhan produksi ternak dan pertanian semakin berlanjut. Pengembangan potensi sumberdaya peternak sebagai upaya untuk peningkatan daya saing peternakan. Teknologi dapat diterapkan melalui kelompok peternak, gunanya untuk perbaikan skala usaha, sehingga dapat dicapai keuntungannya (Rusdiana et al., 2018). Menurut Ilham et al., (2008) bahwa, hampir 90\% peternak rakyat cara usahanya masih tradisional dan selebihnya perusahaan penggemukan sapi potong (feedloter). Difervikasi usaha tanaman jagung dan sapi Bali peternak akan memperoleh keuntungan ganda. Menurut Idris et al., (2017) bahwa, melalui difersivikasi usaha, peternak selain meningkatya pendapatan, juga 
kemandirian peternak untuk usaha meningkat. Usaha tanaman jagung, selain produksi jagung yang di hasilkan juga limbahnya dapat dimanfaatkan sebagai pakan sapi Bali. Difersivikasi usaha tanaman pangan sudah umum diusahakan oleh setiap peternak di pedesaan baik sebagai usaha pokok maupun usaha sampingan (Rusdiana dan Soeharsono 2017).

Difersivikasi usaha sudah berkembang dan muncul istilah pola tanam (cropping pattern), sistem usaha tani farming system dan terakhir sistem integrasi ternak atau CLS (crop livestock system) (Diwyanto et al., 2010). Pola usaha tersebut dan sudah banyak diterapkan dan mengarah pada usahatani dengan sistem Low External Input Sustainable Agriculture (LEISA) (Diwyanto, 2008).Usaha pertanian terpadu di Indonesia menerapkan sistem integrasi tanaman dengan ternak "on station multiple cropping. Untuk meningkatkan kesejahteran peternak melalui peningkatan pengembangan usaha pertanian dan peternakan, sudah banyak dilakukan oleh Pemerintah (Rasyid, 2012). Untuk peningkatan produksi dan produktivitas maupun kualitasnya harus ditunjang dengan sarana dan prasarana yang mendukung untuk keberhasilan usaha tani dan ternak (Rusdiana et al., 2016b). Dikemukakan yang sama oleh Atmakusuma et al., (2011) dan Rusdiana et al., (2014) bahwa, usaha sapi potong dapat diushakann dengan manajemen yang baik, dapat dipertimbangkan dengan kemampuan peternak melalui modal yang dimilikinya.

Dikemukakan yang sama oleh Suryana (2009); Hoddi et al., (2011) dan Prastiti et al., (2012) bahwa, untuk meningkatkan nilai ekonomi peternak, maka usaha dapat dilakukan melalui difersivikasi tanaman jagung dan sapi potong atau usaha lainnya. Melalui difersivikasi tanaman jagung dan sapi Bali dapat menunjang kecukupan pakan dan meningkatnya produktivitas sapi potong Bali. Usaha sapi potong dan jagung merupakan peluang usaha yang dapat dilakukan oleh setiap peternak dan sebagai upaya untuk meningkatkan pendapatan. Berdasarkan permasalahan tersebut di atas, maka perlu dilakukan penelitian mengenai diferrsivikasi usaha tanaman jagung dan sapi potong yang dapat meningkatkan pendapatan peternak. Tujuan tulisan ini adalah untuk mengetahui peningkatan nilai 
ekonomi melalui difersivikasi usaha tanaman pangan dan sapi Bali di peternak, sehingga penelitian ini perlu dilakukan.

\section{METODE PENELITIAN}

\section{Lokasi dan Waktu Penelitian}

Penelitian ini dilakukan di Desa Maccini Baji Kecamatan Bajeng Kabupaten Gowa Sulawesi Selatan 2018. Penelitian menggunakan metoda survei dengan menggunakan kuisioner dan wawancara terhadap 26 petenak sapi Bali. Lokasi penelitian pada agroekosistem lahan pertaniandan usaha sapi Bali. Data yang dikumpulkan meliputi data sekunder dan data primer. Data primer diperoleh dari peternak dan data sekunder diperoleh dari Dinas Pertanian, Peternakan dan Kesehatan Hewan Kabupaten Gowa. Sedangkan data primer bersumber dari responden peternak sapi Bali. Data dianalisis secara deskriptif, kuantitatif dan analisis ekonomi.

\section{Analisis Data}

Data yang diukur adalah parameter dalam bentuk magnitude yang dipakai untuk menghitung parameter tingkat penggunaan tenaga kerja peternak dan nilai ekonomi peternak. Nilai ekonomi yang dipeoleh peternak dilihat dari tingkat pendapatan nominal/riil. Pengeluaran nominal/riil pada biaya produksi usaha tanaman pangan dan sapi Bali. Analisis statistik deskriptif untuk mengethaui nilai ekonomi dimasing-masing usaha dengan rumus:

$$
\bar{X}=\frac{\sum x_{i}}{N}
$$

dimana: $\bar{X}=$ Rata-rata tingkat kepemilikan lahan untuk usaha tanaman jagung, produktivitas tenaga kerja peternak

$\mathrm{x}_{\mathrm{i}}=$ Tingkat pendapatan secara nominal/riil dan tingkat pengeluaran nominal/riil dari usaha tanaman jagung dan sapi Bali ke-i;

$\sum x_{i}=$ Total pengeluaran nominal/riil dan profitabilitas difersivikasi usaha;

$\mathrm{N}=$ Jumlah peterrnak sampel.

Untuk mengetahui tingkat produktivitas waktu kerja peternak dihitung berdasaran rumus : 


$$
\vec{W}=\frac{\sum Y}{A K}
$$

dimana : $\bar{W} \quad=$ Produktivitas tenaga kerja peternak

$\sum Y=$ Total pendapatan peternak

AK = Jumlah keluarga peternak yang bekerja pada usaha jagung dan sapi

Bali. profitabilitas usaha digunakan rumus:

$$
\begin{aligned}
& \pi=\mathrm{T}-\mathrm{TC} \ldots \ldots \ldots \ldots . .(1,2,3 \ldots .5) \\
& \pi=\mathrm{P} . \mathrm{Q}-\mathrm{T} \ldots \ldots \ldots \ldots . .(2.4 .6 \ldots 8)
\end{aligned}
$$

dimana: $\pi$ = Keuntungan bersih yang di peroleh peternak

$\mathrm{TR}=$ Keuntuungan kotor peternak

$\mathrm{P}=$ Harga jual hasil pertanian/kg/Rp, harga sapi potong /ekor/Rp

$\mathrm{Q}=$ Jumlah produksi tanaman jagung $/ \mathrm{kg} / \mathrm{Rp}$, jumlah sapi potong yang dijual

$\mathrm{TC}=$ Biaya input ke-i

$\mathrm{TC}=\sum_{i=1}^{n} T C_{i}=$ Total biaya produksi pada suatu usaha

Kelayakan finansial dan secara ekonomi usaha dapat digambarkan besaran biaya yang dikeluarkan selama usaha berlangsung (Ustriyana, 2015). Biasanya biaya produksi untuk penyediaan pakan, bibit dan tenaga kerja sangat tinggi dan sebagai input utama sehingga perlu perhitungan yang baik (Rusdiana dan Soeharsono, 2017b). Untuk mengetahui besaran biaya tenaga kerja peternak selama satu tahun dihitung berdsarkan hasil perhitungan (Rusdiana et al., 2019). Usaha sapi Bali dan tanaman jagung selama satu tahun dapat dihitung berdasarkan nilai $\mathrm{R} / \mathrm{C}$ ratio (Rohaeni et al., 2006); dan (Rusdiana et al., 2017). Analisis kelayakan finansial usaha sapi Bali dan tanaman pangan dapat dihitungn untung dan rugi dengan menggunakan indikator analisis R/C (Rusdiana dan Soeharsono 2017a).

\section{Model Pendugaan pada Fungsi Produksi}

Untuk melihat fungsi produksi pada difersivikasi usaha digunakan model Stochastic Frontier Cobb-Douglas (Maximum Likeliood Estimation meroda MLE) yang merupakan model untuk mengetimasi keseluruhan parameter pungsi produksi pada kegiatan usaha. intersep dan vareiabel error dan inefisiensi usaha Selain itu juga 
akan dilihat dari beberapa variabel yang berpengaruh terhadap faktor-faktor penduga pada karakteristik pada difersivikasi usaha di peternak $\left(\mathrm{x}_{\mathrm{a}}, \mathrm{x}_{\mathrm{b}} \ldots . . \mathrm{x}_{\mathrm{f}}\right)$. Faktor-faktor tersebut akan dianalisis dengan menggunakan regresi linear berganda Uji t. Dintaranya untuk produksi usaha tanaman jagung $\left(\mathrm{q}_{1}, \mathrm{q}_{2}, \mathrm{a}_{3} \ldots . . \mathrm{q}, \mathrm{q}_{10}, \mathrm{q}_{11}\right)$ sebagai peubah. Pada biaya produksi usaha sapi Bali $\left(\mathrm{z}_{1}, \mathrm{z}_{2}, \ldots . . \mathrm{z}_{5}\right)$ sebagai sebagai peubah. Besarnya pengaruh antara variabel bebas ( $\mathrm{q}$ dan $\mathrm{z}$, ) dengan variabel terikat ( $\mathrm{x}$ dan $\mathrm{y}$ ) kemudian ditenntukan nilai koefisien regresi dimasing-masing variabel.

\section{HASIL DAN PEMBAHASAN}

\section{Deskripsi Peternak}

Pada dasarnnya pelaku ekonomi dan khususnya peternak, dapat memanfaatkan peluang pasar. Peluang tersebut dimanfaatkan oleh setiap petenak untuk menjua hasil produksi pertanian dan sapi Bali. Hasil penelitian dengan peternak dapat danalisis dan secara enpiris digambarkan bahwa dari ragam peternak terdiri dari : petani, buruh tani, pedagang pengumpul atau blantik desa, pedagang, dan pekerja lainnya. Sapi Bali yang dipelihara oleh setiap peternak biasnya saat akan dijual pada umur jantan dan betina berbagai umur atau induk yang sudah tidak dapat berproduksi lagi atau afkir. Penjualnnya dapat dilakukan antara peternak dan pedagang desa, dimana peternak biasanya datang kelokasi peternak. Sebagian peternak usaha memelihara sapi Bali jantan untuk dibesarkann dengan waktu yang ditentukan antara 3-4 bulan, setelah sapi dianggap sudah besar ata gemuk kemudian di jual. harga penjualan sapi atas dasar kesepakatan bersama antara tengulakdan peternak, diamana keduanya sama-sama merasa untung dan tidak ada yang dirugian. Biasanya biaya yang dikeluarkan oleh peternak sebesar antara 2,5-5\% tergatung besar kecilnya sapi dan dihitung berdasarkan harga jual pasar ternak. Maksudanya untuk resiko transpot yang ditanggung oleh penjual, sehingga pembeli tidak merasa dibebani oleh biaya tarnspot lokal. Kesepakatan jual beli sapi di peternak dengan pedagang ternak sudah berjalan cukup lama, sejak jaman nenek moyang terdahulu.

\section{Manfaat Limbah Tanaman Jagung}


Difersivikasi tanaman jagung dan sapi Bali, dapat dilihat dari aspek penerapan cara usahanya sangt mudah, sehingg hampir semua peternak mengusahknnya. Peternak sudah berpengalaman baik usaha tanaman jangung maupun usaha sapi Bali. Hasil dari tanamana jagung yang dihasilkan produksi jagung, juga limbah jerami jagung dapat di manfaarkan sebagai pakan sapi Bali milik peternak. Limbah sapi di manfaatkan sebagai pupuk kandang untuk lahan pertanian milik peternak. Beberapa manfaat dari tanamana jagung yang dapat dimanfaatkan sebagai penyedia pakan harian pda sapi Bali, diantaranya adalah : jerami, tongkol jagung dan klobot. Pemanfaatan limbah tanaman jagung terlihat pada Tabel.1.

Tabel. 1. Pemanfaatan limbah tanaman jangung

\begin{tabular}{lccc}
\hline \multirow{2}{*}{ Pemanfatan } & \multicolumn{3}{c}{ Limbah tanaman jagung $(\mathrm{n}-26)$} \\
& Jerami & Tongkol & Klobot \\
\hline Sebagai pakan ternak & $26(100 \%)$ & $5(19,23 \%)$ & $26(100 \%)$ \\
sebagai pupuk organik & $5(19,23 \%)$ & $3(11,53 \%)$ & $6(23,08 \%)$ \\
dibakar tidak dimakan & $5(19,23 \%)$ & $12(46,15 \%)$ & $7(26,92 \%)$ \\
\hline
\end{tabular}

Tabel.1, menunjukkan bahwa, limbah dari tanaman jagung yang banyak digunakan sebagai pakan sapi Bali adalah jerami dan klobot 100\%. Sisanya sebagai pupuk organik dan di bakar atau tidak dimakan. Jerami jagung sangat bermanfaat baik untuk pakan sapi Bali maupun untuk kesuburan tanah juga dibakar untuk menghangatkan sapi pada saat di kandangkan.

\section{Model pendugaan pada karakeristik peternak}

Pada model pendugaan tersebut pada dasarnya difersivikasi usaha pertanian dan sapi Bali yang sudah lama di usahakan . Namun cara usaha belum mengarah pada usaha komersial, sebatas usaha sampingan, tabungan dan pengisi waktu. Faktorfaktor yang berpengaruh terhadap efisiensi usaha, terkadang menggambarkan hasil yang hampir sama nilai riil yang diperoleh peternak. Untuk meningkatkan pendapatan peternak maka, usaha pertanian dan sapi Bali, perlu dukungan melalui kebijakan Pemerintah serta kelembagaan peternak. Semangat peternak untuk berusaha menjadi salah satu pemicu dalam meningkatkan nilai ekonomi peternak, ada sebagian 
peternak yang mempunyai lahan yang cukup luas. Maju mundurnya usaha tergantung kemampuan, kemauan peternak itu sendiri serta didukung dengan sarana dan prasaran, modal dan lain sebagainya. Ketimpangan pada kondisi pendidikan, umur dan pengalaman bertani atau beternak adalah suatu karakter peternak yang perlu dipertahankan pada kondisi usaha. Pendugaan pada karakteristik peternak pada difersivikasi usaha terlihat pada Tabel.2.

Tabel.2. Faktor Pendugaan karakteristik peternak

\begin{tabular}{llll}
\hline Varabel & Koefisien & t-ratio & standar-error \\
\hline Umur peternak $\left(\mathrm{x}_{\mathrm{a}}\right)$ & $0.0345^{* * *}$ & 2.122 & 0.001 \\
Pendidikan peternak $\left(\mathrm{x}_{\mathrm{b}}\right)$ & $-0.0242^{* *}$ & -2.135 & 0.001 \\
Pengalaman peternak $\left(\mathrm{x}_{\mathrm{c}}\right)$ & $0.0445^{* * *}$ & -0.651 & 0.001 \\
Tanggungan keluarga $\left(\mathrm{x}_{\mathrm{d}}\right)$ & $0.0134^{*}$ & -0.041 & 0.013 \\
Dummy pendidikan $\left(\mathrm{x}_{\mathrm{e}}\right)$ & 0.001 & 0.134 & 0.012 \\
Dummy pendapatan $\left(\mathrm{x}_{\mathrm{f}}\right)$ & 0.000 & 0.000 & 0.017 \\
\hline
\end{tabular}

Keterangan : ***) Signifikan taraf kepercayaan 10\%

**) Signifikan taraf kepercayaan 5\%

*) tidak signifikan taraf kepercayaan $5 \%$ dan $10 \%$

Tabel.2, menunjukkan bahwa, aktivits peternak saling berpengaruh diantara varabel-variabel. Faktor umur dan pengalaman beternak, yang sangat menunjang meningkatnya kemajuan usaha. Diantara variabel dan tidak mengakibatkan difersifikasi usaha tanaman jagung dan sapi Bali menurun. Malah sebaliknya umur peternak masih produuktif, kemudian ditinjang dengan pengalaman beternak yang cukup lama, pendidikan peternak yang masih rendah tidak berpengaruh nyata terhadap usaha $(\mathrm{P}>0,05)$. Begitu pula dengan lahan pertanian yang diolah masih rendah, kadang sebagai tenaga buruh tani juga tidak berpengaruh nyata $(P>0,05)$, karena pengalaman beternak cukup tinggi sekitar 16-31 tahun. Umur peternak masih produktif antara 43-51 tahun, sehingga peternak masih dapat menerima sentuhan teknologi dan semangat kerja peternak tinggi untuk meningkatkan usahanya.

Menurut Rohi et al., (2018) bahwa, peternak dengan pendidikan yang lebih tinggi akan lebih mudah untuk menyerap teknologi baru dan akan mampu mengakses informasi yang lebih baik. Biasanya pola pikir pada umur yang lebih tua akan 
bijaksana dalam membuat keputusan, sehingga hal-hal yang menyangut keberlangsunga hidup akan terperoses lebih baik. Dikemukakan bersama oleh Gul et al., (2009); Otitiju dan Arene (2010) bahwa, untuk faktor usia peternak sangat berpengaruh positif terhadap efisiensi usaha dan secara teknis dapat meningkatkan usaha.

\section{Faktor-faktor penduga pada biaya produksi}

Faktor penduga pada biaya produksi difersivikasi usaha tanaman jagung dan sapi Bali dapat dihitung berdasarkan nilai riil yang di keluaran paa setiap biaya produksi. Biaya prodksi dapat diimbangi dengan harga jual hasil produksi pertanian maupun hasil ternak. Keuntungan yang diperoleh peternak, tentunya akan dilihat dari seberapa besar biaya produksi yang dikeluarkan selama usaha. Kemudian diimbangi dengan nilai riil dari pendapatan kotor yang diperoleh selama usaha. keuntungan akan diperoleh secara riil apabila biata produksi lebih rendah daripada pendpatan bersiah selama usaha, sehngga peternak mendapat keuntungan optimal. Faktor yang mempengaruhi pada biaya produksi di peternak sebagai variabel (Y). Model penduga pada setiap variabel usaha diantaranya luas lahan yang digunakan $\left(\mathrm{q}_{2}\right)$, biaya pembelian bibit jagung/benih $\left(\mathrm{q}_{3}\right)$, biaya pupuk urea $\left(\mathrm{q}_{4}\right)$, biaya $\mathrm{Hcl}\left(\mathrm{q}_{5}\right)$, biaya pupuk kandang ayam $\left(\mathrm{q}_{6}\right)$, biaya pupuk kandang sapi $\left(\mathrm{q}_{7}\right)$, biaya pestisida $\left(\mathrm{q}_{8}\right)$, biaya semprot ( $\left.\mathrm{q}_{9}\right)$, biaya tidak terduga ( $\left.\mathrm{q}_{10}\right)$ biaya tenaga kerja peternak ( $\left.\mathrm{q}_{11}\right)$.

Faktor penduga dari setiap variabel akan saling mempengaruhi satu sama lainnya. Namun dapat diasumsikan dari setiap faktor sebagai penduga untuk meminalisir dari setiap nilai biaya produksi. Model penduga dapat dibuktikan pada setiap melalui biaya produksi yang dikeluarkan. Diantaranya adalah untuk pembibitan secara bersamaan pada variabel pembelian bibit, pakan, obat-obatan, tenaga kerja dan sewa lahan. Biaya produksi memberikan pengaruh secara signifikan terhadap keuntungan peternakan. Model penduga pada setiap faktor produksi difersivikasi usaha tanaman jagung terlihat pada Tabel.3. 
Tabel.3. Model pendugaan fungsi produksi difersivikasi usaha jagung

\begin{tabular}{|c|c|c|c|}
\hline Variabel & Koefisien & t.hitung & Standar-error \\
\hline Konstanta $\left(\mathrm{q}_{1)}\right.$ & 2.414 & 1.031 & 0.002 \\
\hline Luas lahan $\left(\mathrm{q}_{2}\right)$ & $0.161 * * *$ & 1.077 & 0.001 \\
\hline $\operatorname{Benih}\left(\mathrm{q}_{3}\right)$ & $0.554 * * *$ & 1.081 & 0.002 \\
\hline Urea $\left(q_{4}\right)$ & $0.313 * *$ & 1.091 & 0.001 \\
\hline $\operatorname{Hcl}\left(q_{5}\right)$ & $0.181^{* *}$ & 1.032 & 0.001 \\
\hline Pupuk kandang ayam (q6) & $0.110^{*}$ & 1.051 & 0.000 \\
\hline Pupuk kadang sapi $\left(\mathrm{q}_{7}\right)$ & $0.142 *$ & 1.031 & 0.002 \\
\hline Pestisida $\left(\mathrm{q}_{8}\right)$ & 0.151 & 0.414 & 0.002 \\
\hline Biaya semprot (q9) & 0.292 & 1.033 & 0.000 \\
\hline Biaya tidak terduga (q10) & 0.252 & 1.051 & 0.002 \\
\hline Tenaga kerja $\left(\mathrm{q}_{11}\right)$ & 0.226 & 0.012 & 0.002 \\
\hline Sigma Square & 0.655 & 2.171 & 0.071 \\
\hline Gamma & 0.516 & 1.159 & 0.415 \\
\hline Log Likelihood Function & 2.213 & & \\
\hline LR Test of the one-sides error & 2.814 & & \\
\hline
\end{tabular}

Tabel.3, menjukkan bahwa, luas lahan $\left(\mathrm{q}_{1}\right)$ berpengaruh nyata pada $(\mathrm{P}>0,05)$ terhadap variabel lainnya. Kemudian biaya untuk pembelian pupuk kimia sperti urea $\mathrm{Hcl}$, pupuk kandang dan tenaga kerrja berpengaruh pada usaha tanaman jangung nyata $(\mathrm{P}<0,05)$. Menurut Rusdiana et al., (2014), biaya tenaga kerja peternak bila dihitung berdasarkan jumlah biaya yang dikeluarkan selama satu tahun berpengaruh setiap faktor froduksi. Biaya pembelian bibit atau benih jagung sebesaar 0,554, pembelian urea, 0,313, pembelian Hcl 0,181, pupuk kandang, 0,110, 0,141, pestisida 0,151 , biaya semprot 0,292 , biaya tidak terduga 0,252 dan biaya tenaga kerja0,226 Hasil perhitungan menunjukkan nilai sebesar 2.213 dengan nilai staandar error 0,000. Pengeluaran biaya pada variabel tersebut dapat dilihat dari masing-masing faktor. Peternak menganggap semua biaya yang dikeluarkan adalah biaya ritin yang perlu dikeluarkan setap usaha berlangsung. Perhitungan biaya dapat diminalisir dengan menghitung semua biaya yang akan di keluarkan dari setiap pengeluara biaya produksi pada usaha tanaman jagung. 
Kemudian untuk melihat variabel dari setiap biaya produksi usaha sapi Bali akan dilihat dari masing-masing faktor biaya. Faktor biaya sebagai penentua semua biaya yang dikeluarkan dari setiap proses produksi. Faktor yang mempengaruhi pada biaya produksi di peternak sebagai variabel (Y). Model penduga pada setiap variabel usaha diantaranya biaya penyusutan induk sapi Bali $\left(\mathrm{z}_{1}\right)$, biaya penyusutan kandang $\left(\mathrm{z}_{2}\right)$, biaya pakan jerami jagung $\left(\mathrm{z}_{3}\right)$, biaya teaga kerja $\left(\mathrm{z}_{4}\right)$ biaya obat-obatan $\left(\mathrm{z}_{5}\right)$ dan biaya peralatan kandang habis pakai $\left(\mathrm{z}_{6}\right)$. Faktor penduga dari setiap variabel akan saling mempengaruhi satu sama lainnya. Namun dapat diasumsikan dari setiap faktor biaya yang dikeluarkan dan sebagai penduga untuk fungsi produksi usaha. Model penduga dapat dibuktikan pada setiap pengeluaran biaya produksi yang terlihat pada Tabl.4.

Tabel.4. Model pendugaan fungsi produksi difersivikasi usaha sapi Bali

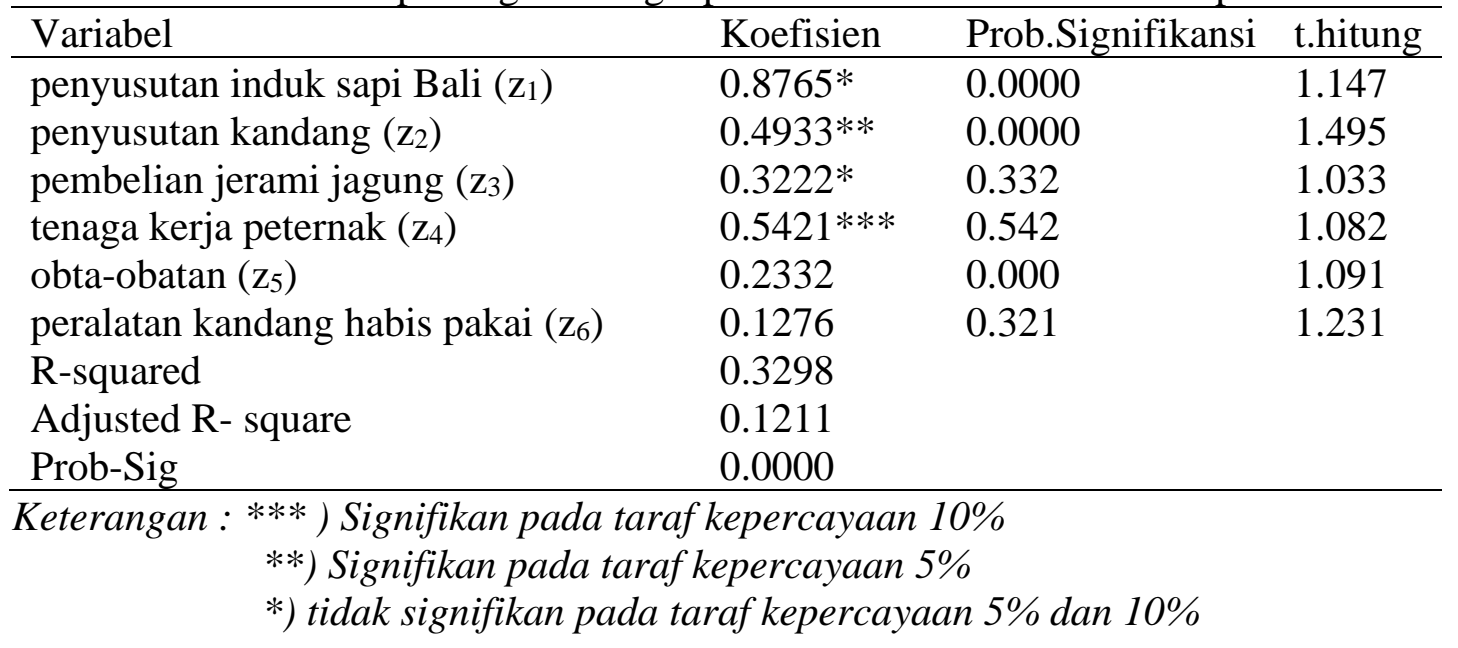

Tabel.4, menjukkan bahwa, variabel penyusuta induk sapi Bali dan penysututan kandang sebagai diasumsikan kedalam biaya produksi. Biaya pembelian bibit induk sapi Bali tidak diasmsikan kedalam biaya produksi. Biaya pembelian sapi diasumsikan kedalam biaya penysutuasn yang dihitung selama 1 tahun dengan biaya 2,5\%/ttahun. Artinya faktor produksi pada biaya usaha sapi Bali aadalah untuk (z1) dan $\left(\mathrm{Z}_{2}\right)$ saling berpengaruh nyata pada $(\mathrm{P}<0,05)$ terhadap variabel biaya produksi. Kemudian biaya yang berpengaruh pada usaha sapi Bali $\left(\mathrm{X}_{3}\right)$ pada tenaga kerja. 
Menurut Rusdiana et al., 2019)), biaya tenaga kerja peternak sapi bila dihirung berdasarkan jumlah biaya yang dikeluarkan selama satu tahun. Biaya tenaga kerja (z4) sebesar 0.542. Biaya pembelian pakan jerami jagung $\left(\mathrm{x}_{3}\right)$ sebesar 0.3222 Biaya pemeblian obat-obatan $\left(\mathrm{z}_{5}\right)$ sebesar 0.2332. dan biaya peralatan kandang $\left(\mathrm{z}_{6}\right)$ sebesar 0.1276. Hasil perhitungan menunjukkan nilai sebesar 0.3298 dengan nilai sebesar 0,000. Usaha sapi Bali dapat dipengaruhi oleh beberapa faktor atau biaya sebagai variabel selama satu tahun. Apabila pendapatan lebih rendah kemungkinan disebabkan biaya produksi lebih tinggi, dan nilai jual sapi Bali.

\section{Biaya Tenaga Kerja Peternak}

Biaya tenaga kerja peternak umumnya dibayarkan setelah pekerjaan selesai atau dibayarkan harian, mingguan dan ada juga dibayar secara tunai. Di daerah penelitian terindikasi bahwa tenaga kerja kelompok peterkak tidak sulit karena hampir 95\% penduduknya bekerja sebagai petani dan peternak. Usaha prioritas pertanian dan usaha sapi Bali yang umum diusahakan oleh peternak di setiap wilayah pedesaan tanaman pangan dan ternak (Rusdiana dan Adawiyah 2013). Usaha pemeliharaan sapi Bali memerlukan kualitas dan intensitas kerja yang tinggi sehingga menuntut tenaga kerja besar yang biasa di penuhi oleh peternak. Perkembangan usaha peternak tidak dapat dilepaskan dari kemajuan teknologi dan tersedianya sumberdaya alam, manusia dan dukungan agroekostem (Rusdiana dan Maesya 2017). Tenaga kerja peternak untuk laki-laki dialokasikan sebagai tenaga utama dan anak, istri sebagai tenaga kerja tambahan. Waktu kerja peternak terlihat pada Tabel.5.

Tabel.5. Waktu kerja peternak usaha tanaman jagug dan sapi Bali

\begin{tabular}{lclc}
\hline Jenis pekerjaan & $\begin{array}{c}\text { Jagung } \\
\text { (jam/tahun) } \pm \text { Sd }\end{array}$ & Jenis pekerjaan & $\begin{array}{c}\text { Sapi potong } \\
\text { (jam/tahun) } \pm \text { Sd }\end{array}$ \\
\hline Pengolahan lahan & $24,14 \pm 0,54$ & Menggembalakan & $52,5 \pm 0,74$ \\
Penanaman & $21,11 \pm 0,48$ & Mencari rumput & $12,5 \pm 0,28$ \\
Pemupukan & $7,6 \pm 0,23$ & Memberikan pakan & $21,5 \pm 0,41$ \\
Penyiangan & $6,7 \pm 0,21$ & Membersihkan kandang & $22,3 \pm 0,51$ \\
Pemberantasan hama & $5,8 \pm 0,18$ & Merawat ternak & $9,8 \pm 0,23$ \\
Panen & $9,1 \pm 0,26$ & Menjual ternak & $7,2 \pm 0,26$ \\
Jumlah & $74,22 \pm 5,31$ & Jumlah & $125,5 \pm 20,79$ \\
\hline
\end{tabular}


Tabel.5, menujukkan usaha tanaman jangung waktu yang dikerjakan cukup banyak adalah saat pengolahan lahan sebesar $24,14 \pm 0,54$. Kemduian pada usaha sapi Bali waktu yang digunakan cukup banyak adalah menggembalakan sebesar $52,5 \pm 0,74$. Proses panen tanaman jagung tergantung kondisi alam, luasan lahan yang diusahakan dan biasanya dalam 1 tahun 3 kali tanam. Sebagian besar peternak melakukan usaha tanaman jagung dan usaha sapi Bali degan anak dan istri ada juga sebagian dengan sudara dan tetangga. Waktu kerja untuk usaha tanaman jagung sebanyak 74,22 $\pm 5,31$ Waktu kerja peternak sebanyak $125,5 \pm 20,79$. Tenaga kerja peternak dihitung berdasarkan konversi 1 Hok 6 jam kerja dan biaya yang dikeluarkan sebesar Rp.20.000,-/Hok/hari/kerja. Menurut Dewi et al. (2007) bahwa, tenaga kerja peternak selama proses produksi diawali dengan kegiatan persiapan sampai pemeliharaan hingga akhir pascapanen. Pekerjaan peternak untuk mengolah lahan dapat ditentukan luas lahan, jumlah tenaga keluarga, usia peternak serta ketersediaan waktu kerja yang di gunakan (Rusdiana et al., 2014).

\section{Harga Sapi di Peternak}

Sapi Bali adalah salah satu ternak besar yang bernilai ekonomis yang tinggi,dan sudah banyak diusahakan oleh peternak kecil di pedesaan. Sapi sudah cukup banyak dikenal di masyarakat dan pada umunya sudah mengenalnya. Salah satu bukti demikian pentingnya sapi dalam kebudayaan masyarakat peternak sapi dapat dikatagrikan dari berbagai macam jenis sapi. Umumnya sapi dapat dilihat dari ukuran tubuh, bentuk, tanduk, serta perpaduan warna kulitnya cukup berragam. Postur tubuh dan bobot badan sapi jantan dan betina berbagai umur dapat menentukan nilai jual, namun peran sapi jantan lebih tinggi harga juanya dibanding sapi betina. Pada sapi betina, biasanya ukuran dan bentuk tubuh dan bobot badan betina tidak terlalu diperhitungkan. Dengan dukungan Pemerintah Pusat dan Daerah, yakin peternakan sapi potong Bali dan sapi lainnya dapat meningkatkan kesejahteraan dan juga penyerapan lapangan kerja. Harga sapi Bali di pasaran berkisar antara Rp.10-30 juta/ekor. Rata-rata peternak memelihara jenis sapi Bali, 
PO, Brhaman dan sapi lainnya dan bisanya bobot badan sapi jantan dewasa antara $400-600 \mathrm{~kg} / \mathrm{ekor}$.

Teknik pemeliharaan sapi terus ditingkatkan melalui sumber daya peternak sesuai lokasi. Semua peternak memanfaatkan pakan hijauan yang tumbuh disekitar lingkungan pemukiman penduduk dan tanah lapang. Perlunya dukungan kelembagaan yang menyangkut untuk keberhasilan usaha sapi, diharapkan dengan menggunakan pakan tambahan konsentar dan vitamin agar prduktivitas sapi meningkat. Pemeliharaan sapi Bali yang sedikit per peternak, namun dengan banyaknya peternak yang memelihara akan bertambah secara teknis populasi sapi meningkat. Secara teknis tampaknya tidak terlalu sukar untuk memelihara sapi secara modern, apabila persoalannya bertumpu pada dua hal. Pertama, faktor biologis seperti sifat-sifat alamiah sapi yang membuat peternakan sapi terus berjalan. Kedua, faktor teknologi, seperti keterbatasan bibit unggul, kualitas pakan, perkawinan silang, kurangnya pengetahuan peternak dalam bioteknologi dan agribisnis, sehingga nilai jual sapi di peternak rendah.

\section{Nilai Ekonomi Usaha Tanaman Jagung}

Tanaman jagung berasal dari daerah tropis yang dapat menyesuaikan diri dengan lingkungan di luar daerah tersebut. Tanaman jagung dapat tumbuh pada berbagai macam tanah seperti andosol, latosol, grumosol, tanah berpasir bahkan pada kondisi tanah yang agak kering (Kunjana, 2018). Tanaman jagung sering diusahakan oleh peternak, namun sampai saat ini peternak melakukan usahanya sebatas kemampuan dan keyakinan sendiri. Desa Macinibaji Kecamatan Bajeng Kabupaten Gowa Sulawesi Selatan, mempunyai adaptasi yang cukup baik terhadap tanaman jagung dan sapi Bali. Menurut Rohaeni et al., (2006) bahwa, pupuk kandang dapat memperbaiki sifat fisik dan kimia tanah. Dengan menggunakan pupuk kandang maka selain tanah kembali subur, juga dapat meningkatkan hasil produksi jagung meningkat. Kesuburan tanah dapat juga dipengaruhi oleh kondsi lahan yang optimal, peternak sering menggunakan pupuk kandang, sehingga tanah selamanya baik dan subur. Hasil penelitian Rusdiana et al., (2019) dengan menggunakan pupuk kandang 
tanaman jagung dapat berproduksi sebanyak $1.483 \mathrm{~kg} / \mathrm{ha}$ dan keuntunagn sebesar Rp.1.100.600/panen dengan R/C sebesar 1,2.

Menurut Fadwiwati et al., (2013) bahwa suatu usaha pertanian dapat dikatakan efisien apabila, memiliki nilai rata-rata diatas $>0.70$. Menurut Rohi et al., (2018) dan Sodiq et al., (2017) ada perbedaan tingkat efisiensi usaha yang dilakukan oleh setiap peternak sehingga dapat dimungkinkan niai ekonomi peternak akan berbeda. Efisiensi teknis menjadi syarat keharusan untuk mengukur efisiensi harga dan efisiensi ekonomi. Efisiensi teknis mengharuskan atau mensyaratkan adanya proses produksi yang dapat memanfaatkan input yang lebih sedikit demi menghasilkan output dalam jumlah yang sama (Nugroho, 2015). Untuk usaha tanaman jagung tentunya biaya produksi dapat diperhitungkan sesuai dengan luas lahan yang akan di usahakan. Asumsi harga jagung yang berlaku saat ini di peternak sebesar Rp.3.450,-/kg yang diambil langsung dari kebun. Asumsi biaya untuk usaha tanaman jagung untuk biaya pembelian bibit atau benih jagung sebanyak 12,2 $\mathrm{kg}$ dengan harag sebesar Rp.41.500,-/kg atau sebesar Rp.518.750.

Biaya untuk pembelian pupuk kimia urea sebanyak 1 zak dengan harag Rp.100.000,-/zak atau sebsar Rp.100.000,-- Biaya untuk pembelan pupukkimia Hcl sebanyak 2 zak dengan harga sebesar Rp.200.000,-/zak atau sebesar Rp.100.000,-. Biaya pembelian pupuk kandang ayam sebanyak 2 ton dengan harga sebesar Rp.150,/kg atau sebesar Rp.300.000,-. Biaya pemeblian pupuk sapi sebanyak 1 ton dengan harga Rp.150,-/kg atau sebesar Rp.150.000,-.Biaya pembelian insektisida sebanyak 4 liter dengan harga sebesar Rp.50.000,-/liter atau sebesar Rp.200.000,-. Biaya ongkos menyemprot tanaman jagung untuk 1 orang sebesar Rp.150.000,. Baya tidak terdga sebesar Rp.50.000,- dan biaya tenaga kerja pternak sekitar 74,45 Hok/ha dengan upah kerja sebesar Rp.20.000,-/hari atau sebesar Rp.1.489.000,-/panen. Jumlah biaya produksi sebesar Rp.3.157.750. Hasil penjulan produksi jagung sebanyak 1.271.5 $\mathrm{kg} /$ panen dengan rata-rata harga sebesar Rp.3.550,-/kg atau sebesar Rp.4.513.825,/panen. Jumlah keuntunagn bersih sebesar Rp. 1.356.075 dengan nilai R/C sebsar 1,4

\section{Nilai Ekonomi Usaha Sapi Bali}


Usaha pemeliharaan ternak sapi potong di peternak dengan cara dikandangkan dan digembalakan atau keduanya sebagai berikut. Asumsi biaya untuk usaha pemeliharaan sapi bali betina induk dan calon induk dengan rata-rata harga sebesar Rp.10.500.000,-/ekor atau sebesar Rp.31.500.000,-. Biaya pembuatan kandang dengan rata-rata sebesar Rp.2.100.000,-/unit. Biaya penyusutan bibit sapi Bali sebesar 2,5\%/tahun atau sebesar Rp.787.500,-. Biaya penyusutan kadang selama 5 tahun sebesar Rp.420.000,-/tahun. Jumlah biaya penyusutan sebesar Rp. 1.207.500,/tahun. Biaya tenaga kerja peternak sebanyak 125,5 Hok//hari/tahun dengan harga upah sebesar Rp.20.000,-/hari atau sebesar Rp.2.516.000,-/tahun. Biaya peralatan kandang sebesar Rp.185.000,-/tahun. Biaya pembelian pakan jerami jagung sebanyak 10/hari x 3 ekor x harga Rp.50/kg x tahun sebesar Rp.540.000. Biaya pembelian obatobatan sebesar Rp.115.000,-/paket/tahun. Jumlah biaya produksi sebesar Rp.3.356.000,-/tahun. Jumlah biaya penyusutan dan biaya produksi sebesar. Rp.4.563.500,-/tahun.

Hasil penjulan pedet sapi Bali jantan dan betina sebanyak 2 ekor rata-rata umur antara 4-5 bulan dengan rata-rata harga sebesar Rp.4.455.000,-/ekor. Jumlah keuntungan kotor sebesar Rp.8.910.000,-/tahun. Jumlah keuntungan bersih sebsar Rp.4.346.500,-/tahun/peternak denagn nila R/Csebsar 2.07. Menurut Sodiq et al., (2017) bahwa, untuk usaha pembibitan sapi potong berbeda dengan usaha penggemukan, sehingga nilai peningkatan ekonominya akan berbeda. Nilai ekonomi difersivikasi usaha tanaman jagung dan sapi Bali di peternak terlihat pada Tabel.6.

Tabel.6 Analisis ekonomi difersivikasi usaha di peternak

\begin{tabular}{lll}
\hline \multicolumn{1}{c}{ Uraian } & Jagung (Jumlah/Rp) & \multicolumn{1}{c}{$\begin{array}{c}\text { Sapi Bali } \\
\text { (Jumlah/Rp) }\end{array}$} \\
\hline Biaya penyusutan dan biaya produksi & 3.157 .750 & 4.563 .500 \\
Pedapatan kotor/tahun & 4.513 .825 & 8.910 .000 \\
Pendapatan bersih/tahun & 1.356 .075 & 4.346 .500 \\
R/C & 1,4 & 2,07 \\
\hline
\end{tabular}

Tabel.6, menujukkan bahwa biaya produksi dari setiap pengeluaran usaha tanaman jagung sebesar Rp.3.156.750,-/panen. Keuntungan bersih sebesar Rp. 
1.356.075,- dengan nilai R/C sebesar 1,4. Hasil penelitian Rusdiana et al., (2019) usaha jagung di peternak dengan keuntungan bersih sebesar Rp.1.1.00.600 dengan nilai R/C sebesar 1,2. Biaya produksi pada usaha sapi Bali sebesar Rp. 4.563.500,/tahun. keuntuang bersih sebsar Rp. 4.346.500,- denagn nilai R/C sebesar 2,07. Sebagian biaya produksi untuk pembelian pakan diasumsikan kedalam biaya tenaga kerja peternak. Nilai jual sapi Bali dapat dipengaruhi oleh umur, bobot badan dan jenis kelamin. Hasil penelitan Rusdiana et al., (2016a) usaha sapi potong dengan cara digembalakan skala 4 ekor, peternak mendapat keuntungan bersih sebesar Rp.3.185.000/tahun dengan R/C sebesar 1,2. Difersivikasi usaha tanaman jagung dan sapi Bali di peternak secara ekonomi layak untuk diushakan kembali, dilihat dari nilai $\mathrm{R} / \mathrm{C}>1$.

\section{KESIMPULAN DAN SARAN}

\section{Kesimpulan}

Lokasi penelitian sangat mendukung untuk erkebangan sapi Bali. Kemudian hasil penelitian dapat disimpulkan difersivikasi usaha tanaman jagung dan sapi Bali dapat peningkatkan nilai ekonomi dan pendapatannya dengan waktu yang berrsamaan. Keuntungan bersih dari usaha tanaman jagung sebesar Rp. 1.356.075,/tahun dengan R/C sebesar 1,4. Keuntungan bersih dari usaha sapi Bali sebesar Rp. 4.346.500,-/tahun dengan R/C sebesar 2,07. Diversifikasi usaha layak untuk dilanjutkan, karena selain untuk mengoptimalkan lahan pertanian juga untuk menanggulangi resiko kegagalan panen. Limbah jerami jagung sebagai pakan sapi Bali, Difersivikasi usaha tanaman jagung dan sapi Bali di peternak secara ekonomi layak untuk diushakan kembali, dilihat dari nilai $\mathrm{R} / \mathrm{C}>1$.

\section{Saran}

Perlu perbaikan diversifikasi usaha tanaman jagung dan sapi Bali, sehingga pendapatan peternak lebih meningkat dan fokus pada usaha tanaman pangan dan sapi Bali. Peternak harus mempertahankan usahanya, karena kondisi lingkungan wilayahnya sebagai lahan pertanain dan usaha sapi Bali, secara tidak langsung akan 
meningkatnya nilai ekonomi peternak. Peran peternak akan menjadi penting dalam peningkakan perekonomian wilayahnya.

\section{UCAPAN TERIMA KASIH}

Terima kasih disampaikan kepada inseminator dan penyuluh dari Dinas Peternakan dan Kesehatan Hewan Kabupaten Gowa Sulawesi Selatan Bapak Ikhasn, SPt dan Bapak Saparuddin, SPt yang telah membantu penelitian ini dan mencari data dan mengolah data, sehingga tulisan ini dapat ditulis dengan baik. Namun makalah ini masih banyak kekuragan-kekurangannya, sehingga makalah ini masih perlu pertimbangan, perbaikan dan saran-sarannya. Terima kasih banyak atas kerja dan batuannya, semoga Allah yang membalas kebaikan Bapak, Aamin

\section{DAFTAR PUSTAKA}

Atmakusuma, J, Harmini \& Ratna W. 2011. Mungkinkah swasembada daging terwujud. Jurnal Risalah Kebijakan Pertanian dan Lingkungan, Departemen Agribisnis, Jurnal Ekonomi Pertanian Fakultas Ekonomi dan Manajemen IPB Bogor, 1(2): 105-109.

Demitria.D., Harianto, Sjafri.M. dan Nunung. 2006. Peran pembangunan sumberdaya manusia dalam peningkatan pendapatan rumah tangga petani di Daerah Istimewa Yogyakarta. Forum Pascasarjana IPB, 33(3):155-164.

Dewi, S., Alam dan Haris. 2007. Analisis titik impas dan sensitivitas terhadap kelayakan finansial usahatni padi sawah. Balai Besar Pengkajian dan Pengembangan Teknologi Pertanian Bogor, Jurnal Pengkajian dan Pengembangan Teknologi Pertanian 10(2):119-125.

Dewi.F dan L. Mairika. 2008. Pemanfaatan limbah pertanian sebagai pakan ruminansia pada peternakan rakyat di Kecamatan Rengat Barat Kabupaten Indragiri Hulu Pakan Baru Riau. Jurnal Peternakan 5(1):28-37.

Diwyanto, K. 2008. Pemanfaatan sumber daya lokal dan inovasi teknologi dalam mendukung pengembangan sapi potong di Indonesia, Jurnal Pengembangan Inovasi Pertanian I(3):173-188.

Diwyanto, K., S, Rusdiana dan B, Wibowo. 2010. Pengembangan agribisnis sapi potong dalam suatu sistem usahatani kelapa terpadu. Wartazoa 20(1):29-40.

Fadwiwati AY, Hartoyo S, Kuncoro SU dan Rusastra IW. 2013. Analisis efisiensi teknis, efisiensi alokatif, dan efisiensi ekonomi usahatani jagung berdasarkan varietas di Provinsi Gorontalo.Jurnal Agro Ekonomi. 32(1): 1-12 
Gul FA, Fung SYK dan Jaggi B. 2009. Earnings quality: Some evidence on the role of auditor tenure and auditors' industry expertise.Journal of Accounting and Economics. 47(3): 265-287

Hoddi, A. H., M. B,. Rombe dan Fahrul. 2011. Analisis pendapatan peternakan sapi potong di Kecamatan Tanete, Kabupaten Barru, Fakultas Peternakan Universitas Hasanuddin Jurnal Agribisnis Peternakan 10(3):98-109.

Ilham, N., Hermanto, Siregar dan D.S. Priyarsono. 2008. Efektivitas kebijakan harga pangan terhadap ketahanan pangan. Jurnal Agro Ekonomi, Pusat Analisis Ekonomin dan Kebijakan Pertanian JAE, 24(2):157-177.

Idris, N., Afriani, H dan Fatati. 2017. Analisis tingkat kemandirian peterni pada pola integrasi ternak sapi dengan perkebunan kelapa Sawit di Propinsi Jambi. Jurnal Ilmiah Ilmu Terapan Universitas Jambi, 1(2):162-169.

Kunjana Gora. 2018. Sistem tanam rapat tingkatkan produktivitas jagung read more at: tersedia di internet https://investor.id/agribusiness/sistemtanam-rapat-tingkatkan-produktivitas-jagung, di akses tgl, 2 Aril 2020,

Idris, N., H, Afriani dan Fatati. 2017. Analisis Tingkat kemandirian peternan pada pola integrasi ternak sapi dengan perkebunan kelapa sawit di Propinsi Jambi. Jurnal Ilmiah Ilmu Terapan Universitas Jambi,.1(2):162-169.

Nugroho Budi Arif. 2015. Analisis pungsi produksi dan efisiensi produksi jagung di Kecamatan Patean Kabupaten Kendal. JEJAK , Journal of Economics and Policy, 8(2): 163-177. Doi:///http/dx.Doi.org/10.15294.jajak.v8i2.6168. http://journal.unnes.ac.id/nju/index.php/jejak,

Otitoju MA and Arene CJ. 2010. Constraints and determinants of technical efficiency in medium-scale soybean production in Benue State, Nigeria. African Journal of Agricultural Research. 5(17): 2276-2280

Prastiti, R. A., W. Rahayu dan A. Wijianto. 2012. Strategi pengembangan agribisnis sapi potong di Kabupaten Blora. Program Studi Agribisnis. Fakultas Pertanian. Universitas Sebelas Maret. Surakarta. Jurnal Agrista,14(2):67-72

Piya S, Kiminami A dan Yagi H. 2012. Comparing the technical efficiency of rice farms in urban and rural areas: A case study from Nepal. Trends in Agricultural Economics. 5(2):48-60.

Rohi Jullyo Gideon, Ratna Winandi dan Anna Fariyanti. 2018. Analisis faktor yang mempengaruhi produksi usahatani jagung serta efisiensi teknis di kabupaten kupang, Forum Agribisnis 8(2):181-187.

Rohaeni, E. Siti., N. Amalia, Sumanto, A. Darmawan dan A. Subhan. 2006. Pengkajian integrasi dan ternak sapi di lahan kering Kabupaten Tanah laut, kalimantan Selatan. Jurnal Pengkajian dan Pengembangan Teknolog Pertanian 9(2):129-139.

Rusdiana, S dan Cut.R.Adawiyah. 2013. Permasalahan ekonomi dan sistem perekonomian hasil produksi pertanian di Indonesia Activita Jurnal Pemberdayaan Mahasiswa dan Masyarakat, 6(2):263-280 
Rusdiana, S., IGM. Budiarsana dan Sumanto. 2014. Analisis pendapatan usaha pertanian dan peternakan kerbau di Kabupaten Lombok Barat (NTB) Jurnal Ekonomi Pertanian, Sumberdaya dan Lingkungan, JAREE IPB 1(2):56-67

Rusdiana, S., R.Hutasoit dan J. Sirait 2016a. Analisis ekonomi usaha sapi potong di lahan perkebunan sawit dan karet. Program Studi Agribisnis Fakultas Pertanian UNS, Jurnal SEPA, 12(2):146-155

Rusdiana, S., U. Adiati dan R. Hutasoit. 2016b. Analisis ekonomi usaha ternak sapi potong berbasis agroekosistem di Indonesia. Jurnal Sosail Ekonomi dan Kebijakan Pertanan. Jurnal Agroekonomika 5(2):137-149.

Rusdiana, S., dan A. Maesya. 2017. Pertumbuhan ekonomi dan kebutuhan pangan di Indonesia. Jurnal Sosail Ekonomi dan Kebijakan Pertanan. Jurnal Agroekonomika 6(1):12-25.

Rusdiana, S. dan Soeharsono. 2017. Farmer group performance bali cattle in Luwu District east: the economic analysis. The International Joural Of Trovical Veterinery and Biomedical Research, The Faculty of Veterinery Medicine Syiah Kuala University, 2(1):18-29

Rusdiana, S dan Soeharsono.2017b. Program Siwab untuk meningkatkan populasi sapi potong dan nilai ekonomi usaha ternak. PSEKP, Forum Agro Ekonomi 35(2):125-137.

Rusdiana, S, Soeharsono and TR. Ferasyi. 2017. Beet catlle busines in dry land area Parangloe Distric Gowa. The International Joural Of Trovical Veterinery and Biomedical Research, The Faculty of Veterinery Medicine Syiah Kuala University, 2(2):11-16.

Rusdiana, S, L. Praharani dan Diana, N. Kusumaningrum 2018. Perbaikan skala usaha sapi potong pada peternak Malingping dan Hasanah di Kabupaten Sukabumi, Jurnal SEPA, 15(1):58-69

Rusdiana, S, E.Sutedi, Umi Adiati dan dan Diana, N. Kusumaningrum 2019. Integrasi usaha tanaman pangan dan sapi potong secara analisis keuntungan pada petani trans,igran di Bengkulu Tengah. Jurnal Vteriner,20(1):74-86

Suryana.2009. Pengembangan usaha ternak sapi potong berorientasi agribisnis dengan pola kemitraan Jurnal Litbang Pertanian, 28(1):29-39

Saptana. 2012. Konsep efisiensi usahatani pangan dan implikasinya bagi peningkatan produktivitas. Forum Agro Ekonomi Pusat Sosial Ekonomi dan kebijakan Pertanian. Jurnal FAE, 30(2):109.128.

Sodiq, A., Suwarno, F.Rizki Fauziyah, Y.N. Wakhidati dan P.Yuwono. 2017. Sistem produksi peternakan sapi potong di pedesaan dan strategi pengembangannya, Jurnal Agripet 17(1):60-66.

Ustriyana, ING. 2015. Agribusiness Model in Rural Community Economic: Indonesia Perspective. African Journal of Agricultural Research. 10(4):174178. 